\title{
Autonomic and respiratory dysfunction in Charcot-Marie-Tooth disease due to Thr124Met mutation in the myelin protein zero gene
}

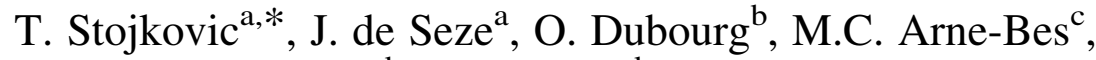 \\ S. Tardieu ${ }^{\mathrm{b}}$, J.C. Hache ${ }^{\mathrm{d}}$, P. Vermersch ${ }^{\mathrm{a}}$ \\ ${ }^{\mathrm{a}}$ Department of Neurology, University of Lille, 59037 Lille Cedex, France \\ ${ }^{\mathrm{b}}$ Institut National de la Recherche Médicale U289, Hôpital de la Salpêtrière, Paris, France \\ ${ }^{\mathrm{c}}$ Department of Neurology, CHU Toulouse-Rangueil, Toulouse, France \\ ${ }^{\mathrm{d}}$ Department of Neuro-ophthalmology, University of Lille, 59037 Lille Cedex, France
}

Accepted 6 May 2003

\begin{abstract}
Objective: To report the clinical and electrophysiological characteristics of a family presenting Charcot-Marie-Tooth disease (CMT) associated with autonomic nervous system disturbances.

Methods: We studied nerve conduction values, postural adaptation, sympathetic skin reflex, the variation in heart rate by the Valsalva ratio and pupillometry in 7 members of a French family in which CMT due to a Thr124Met mutation in the myelin protein zero (MPZ) gene was diagnosed.

Results: Clinical and laboratory evidence of autonomic nervous system disturbances were found in the affected individuals. The clinical phenotype was characterized by sensorimotor peripheral neuropathy, defined as axonal type by electrophysiological studies, and was associated with severe pain, bladder dysfunction, sudorimotor disturbances and abolished pupillary reflex to light. Moreover, two patients had severe restrictive respiratory insufficiency requiring noninvasive mechanical ventilation.

Conclusions: Our study demonstrates that autonomic disturbances may be one of the major clinical signs associated with CMT secondary to $M P Z$ gene mutation in codon 124. Testing of pupillary reflex allows the discrimination of affected and unaffected subjects in our family. However, involvement of the autonomic nervous system in this type of neuropathy is unclear and further studies are required to elucidate the role of the $M P Z$ gene in the autonomic nervous system.

(C) 2003 International Federation of Clinical Neurophysiology. Published by Elsevier Ireland Ltd. All rights reserved.
\end{abstract}

Keywords: Charcot-Marie-Tooth disease; Myelin protein zero; Autonomic nervous system

\section{Introduction}

Hereditary sensory and motor neuropathies (HSMN) or Charcot-Marie-Tooth disease (CMT), are chronic disorders of the peripheral nervous system, causing weakness and sensory impairment. Different forms of HSMN can be distinguished according to the electrophysiological data, the type of inheritance and the mutated gene. CMT1 is the demyelinating form, characterized by motor nerve conduction velocity (MNCV) below $35 \mathrm{~m} / \mathrm{s}$, whereas CMT2 is the axonal form, characterized by normal MNCV (Dyck et al.,

\footnotetext{
* Corresponding author. CHU de Lille, Hôpital Roger Salengro, Service de Neurologie D, 59037 Lille Cedex, France. Tel.: +33-3-20-44-57-65; fax: +33-3-20-44-44-84.

E-mail address: t-stojkovic@chru-lille.fr (T. Stojkovic).
}

1993). CMT2 has been linked to 3 loci on 1p35-36, 3q13q22 and 7p14 (Ben Othmane et al., 1993; Kwon et al., 1995; Ionasescu et al., 1996). CMT1A is mostly caused by a duplication of the PMP22 gene on chromosome 17p11.2p12 (Timmerman et al., 1992; Valentijn et al., 1992). CMT1B is associated with mutations in the myelin protein zero $(M P Z)$ gene on chromosome 1q22-q23 (Hayasaka et al., 1993; Latour et al., 1995). Three clinical and electrophysiological phenotypes have been associated with $M P Z$ gene mutations: CMT1B, which is characterized by slow MNCV $(<25 \mathrm{~m} / \mathrm{s})$ and onset in the first two decades of life, Dejerine-Sottas syndrome with onset in infancy and extremely reduced $\mathrm{MNCV}(<10 \mathrm{~m} / \mathrm{s})$, and congenital hypomyelination (Warner et al., 1996). However, several axonopathies in CMT disease have been associated with 
a mutation in the MPZ gene (Marrosu et al., 1998; Chapon et al., 1999; Mastaglia et al., 1999; Misu et al., 2000; Senderek et al., 2000; Young et al., 2001). Recently, a family with a distinct clinical phenotype characterized by marked sensory abnormalities, deafness, pupillary abnormalities and variable slowing of MNCV was reported to carry a new mutation (Thr124Met) in the MPZ gene (De Jonghe et al., 1999). In the present study, we report the French arm of this family, marked by a particular clinical presentation characterized by severe dysautonomia, pain and respiratory insufficiency.

\section{Methods}

\subsection{Clinical analysis}

The individuals studied are members of the French arm of a family in which a Thr124Met mutation in the $M P Z$ gene was previously discovered in Belgium (De Jonghe et al., 1999). Individuals $\mathrm{II}_{1}, \mathrm{II}_{2}, \mathrm{II}_{3}, \mathrm{II}_{4}, \mathrm{III}_{9}, \mathrm{III}_{10}$ and $\mathrm{III}_{11}$ underwent a complete clinical examination. These individuals were also asked to respond to questions addressing symptoms of pain, orthostatic intolerance and gastrointestinal, bladder and sexual dysfunction.

\subsection{Electrophysiological, respiratory and pathological analysis}

All clinically examined individuals underwent motor and sensory nerve conduction studies of all 4 limbs. Surface electrodes were used to record the compound muscle action potential (CMAP) and the sensory amplitudes of the limbs. Sensory nerve conduction velocity (SNCV) and sensory nerve action potential (SNAP) were obtained using the antidromic method. The latency of the phrenic nerve was evaluated in the affected individuals $\left(\mathrm{II}_{1}\right.$ and $\left.\mathrm{II}_{3}\right)$. The tests were performed with Viking EMG apparatus (Nicolet). Phrenic nerve conduction was assessed as described elsewhere (Cruz-Martinez et al., 2000). Latency was determined from the stimulus artifact to the onset of the negative peak.

Sympathetic skin reflex (SSR) was obtained after placing the active and reference surface electrodes on the palms and dorsum of the hand and the sole and dorsum of the feet, respectively. In all individuals, responses were measured in the upper and lower limbs. Electrical and auditory stimuli were applied to the median nerve at the wrist and the posterior tibial nerve at the ankle. Latency of the SSR was measured from the onset of the stimulus artifact.

Pupillometric tests were performed in all individuals. Pupillary parameters were recorded with a pupillometer (Vision Monitor System, Metrovision, France), which induced a near infrared illumination $(880 \mathrm{~nm})$. Patients were placed $160 \mathrm{~cm}$ from a screen with an angular size of $40^{\circ}$. After 20 min of dark adaptation, 8 uniform flashes of white light with a duration of $1 \mathrm{~s}$ and a mean luminance of
$30 \mathrm{~cd} / \mathrm{m}^{2}$ were produced at $8 \mathrm{~s}$ intervals. The first response was excluded and the following seven responses were averaged. The amplitude and the pupillary light reflex latency (PLRL) were recorded. The PLRL was defined as the time interval between the onset of the stimulation and the beginning of the constriction. The direct PLRL was recorded after stimulating the ipsilateral eye, and the indirect PLRL was recorded on the ipsilateral eye with the eye occluded while stimulating the controlateral eye (De Seze et al., 2001). Orthostatic blood pressure in response to standing was recorded as follows: after an initial $5 \mathrm{~min}$ resting period in the supine position, the individual was tilted upright for $5 \mathrm{~min}$. The heart rate and blood pressure were recorded at $1 \mathrm{~min}$ intervals. Cardiovagal and baroreflex functions were evaluated by the Valsalva ratio using the Valsalva maneuver in affected individuals $\left(\mathrm{II}_{1}\right.$ and $\left.\mathrm{II}_{3}\right)$. The results of each test were compared with a database of normative values (Low, 1993). All individuals were free of any medication that could affect the results of the autonomic tests. Since affected individuals $\left(\mathrm{II}_{1}\right.$ and $\left.\mathrm{II}_{3}\right)$ complained of dyspnea, respiratory function tests, a chest X-ray and an electrocardiogram were also performed. Moreover, a urological examination, bladder ultrasonography and cystometrography were realized in the affected individuals, who both complained of urinary disturbances. The propositus $\left(\mathrm{II}_{3}\right)$ also underwent a nerve biopsy for histopathological analysis.

\subsection{Genetic analysis}

DNA samples from all seven members of our family were analyzed. Exon 3 of $M P Z$ gene was amplified from DNA by intronic primers, as described elsewhere (De Jonghe et al., 1999). PCR products were digested with Nla III (New England Biolabs, USA) for detection of the Thr124Met mutation and then separated on agarose gel stained with ethidium bromide. Since two restriction fragments of 21 and $347 \mathrm{bp}$ were observed in normal controls, the 158 and $189 \mathrm{bp}$ fragments in affected members resulted from an additional Nla III restriction site created by the Thr124Met mutation.

\subsection{Blood test analysis}

Complete blood count, electrolytes, urea, creatinine, liver enzymes, thyroid function, fasting glucose, glycosylated hemoglobin, vitamin B12 level, fluorescent treponemal antibody (FTA), sedimentation rate, serum immunofixation and antinuclear antibodies were performed in all individuals. 


\section{Results}

\subsection{Clinical data}

The pedigree of our family is consistent with an autosomal dominant inherited disease (Fig. 1). Based on family history, the mother of the propositus $\left(\mathrm{I}_{1}\right)$ was known to be affected since she presented bilateral pes cavus and had walking difficulties.

The propositus $\left(\mathrm{II}_{3}\right)$ was a 62-year-old man, $175 \mathrm{~cm}$ tall and weighing $82 \mathrm{~kg}$, who since the age of 40 years had complained of paresthesia, shooting pain and cramps in the lower and upper limbs, which progressively worsened and required major analgesic therapy. At the time of the study, he could walk $100 \mathrm{~m}$ with the aid of canes. On examination, there was marked wasting and weakness of distal muscles, areflexia and bilateral pes cavus. Pain, light touch and vibration perception were severely reduced in the upper and lower limbs. On ophthalmologic examination, the pupils were of normal size $(5 \mathrm{~mm})$ and unresponsive to light but showed normal constriction on convergence, leading to the diagnosis of Argyll-Robertson pupils. Auditory acuity was severely reduced and the patient required hearing aids. He also reported urinary urgency, urge incontinence and erectile dysfunction with frequent episodes of impotence. From the age of 55 years he complained of dyspnea and morning headache and required nocturnal mechanical ventilation.

The sister of the propositus $\left(\mathrm{II}_{1}\right)$ was a 67-year-old woman, $167 \mathrm{~cm}$ tall and weighing $65 \mathrm{~kg}$, who had complained of urinary disturbances from the age of 36 years, requiring catheterization of the bladder every $3 \mathrm{~h}$. Eleven years after the onset of urinary disturbances, she developed paresthesias in the lower limbs followed by weakness and wasting of all 4 limbs. At the time of the study, she could walk $50 \mathrm{~m}$ with the aid of canes. Clinical examination showed distal sensorimotor deficit, areflexia and bilateral pes cavus. Pupils were unresponsive to light. She also presented severe dyspnea and required noninvasive mechanical ventilation with a nasal mask.

At-risk members $\mathrm{II}_{2}, \mathrm{II}_{4}, \mathrm{III}_{9}, \mathrm{III}_{10}$ and $\mathrm{III}_{11}$ did not complain of any symptoms and were normal on clinical examination.

\subsection{Electrophysiological and autonomic function tests}

Nerve conduction velocities, the results of the Valsalva ratio, SSR tests and phrenic nerve latency are shown in Table 1. The MNCV of the median nerve of clinically affected members $\left(\mathrm{II}_{1}, \mathrm{II}_{3}\right)$ ranged from 35 to $46 \mathrm{~m} / \mathrm{s}$. In both these patients, MNCVs and CMAPs were severely reduced in the lower limbs, and sensory responses were almost abolished in the lower limbs and were diminished in the upper limbs, whereas nerve conduction studies were normal in individuals $\mathrm{II}_{2}, \mathrm{III}_{9}, \mathrm{III}_{10}$ and $\mathrm{III}_{11}$. In individual $\mathrm{II}_{4}$, MNCVs were normal but the CMAP of the right median nerve was reduced, as a consequence of a carpal tunnel syndrome. The SNCV of the peroneal nerve of the latter individual was slightly diminished but the SNAP of the peroneal nerve was normal. Affected individuals $\mathrm{II}_{1}, \mathrm{II}_{3}$ also presented an abnormal Valsalva ratio, an absence of SSR and a prolonged latency of the phrenic nerve. Pupillary response to direct light was abolished in affected individuals $\mathrm{II}_{1}$ and $\mathrm{II}_{3}$ (Fig. 2) and normal (latency and amplitude) in individuals $\mathrm{II}_{2}, \mathrm{II}_{4}, \mathrm{III}_{9}, \mathrm{III}_{10}$ and $\mathrm{III}_{11}$. The instillation of diluted pilocarpin $0.1 \%$ in the propositus $\left(\mathrm{II}_{3}\right)$ and his sister $\left(\mathrm{II}_{1}\right)$ induced a rapid and marked miosis, rather suggesting an abnormal parasympathetic response.

Blood pressure and heart rate response to the changing from a supine to a upright position showed a fall in systolic pressure of $25 \mathrm{mmHg}$ and a fall in diastolic pressure of $10 \mathrm{mmHg}$ with no increase in heart rate for the propositus and his affected sister $\left(\mathrm{II}_{1}\right)$. Individuals $\mathrm{II}_{2}, \mathrm{II}_{4}, \mathrm{III}_{9}, \mathrm{III}_{10}$ and $\mathrm{III}_{11}$ had no orthostatic hypotension.

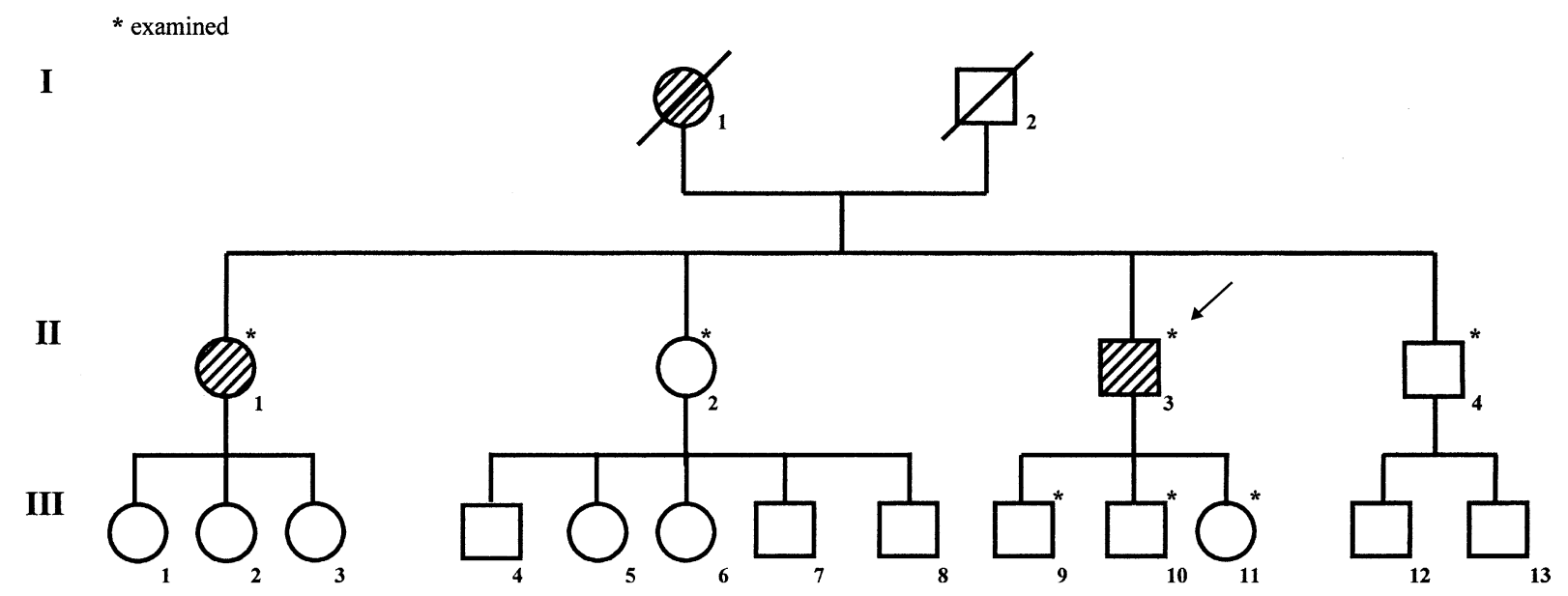

Fig. 1. Pedigree of the family. Darkened figures indicate affected individuals. Examined individuals are indicated with an asterisk. The arrow indicates the proband. 
Table 1

Electrophysiological data of the 7 patients of the family

\begin{tabular}{|c|c|c|c|c|c|c|c|}
\hline Individual/sex & $\mathrm{II}_{1} / \mathrm{F}$ & $\mathrm{II}_{2} / \mathrm{F}$ & $\mathrm{II}_{3} / \mathrm{M}$ & $\mathrm{II}_{4} / \mathrm{M}$ & $\mathrm{III}_{9} / \mathrm{M}$ & $\mathrm{III}_{10} / \mathrm{M}$ & $\mathrm{III}_{11} / \mathrm{F}$ \\
\hline Age/age at onset & $67 / 36$ & 65/As & $62 / 40$ & 58/As & 33/As & 29/As & 26/As \\
\hline \multicolumn{8}{|l|}{ Median } \\
\hline $\operatorname{MCV}(N \geq 48)$ & 57 & 52 & 41 & 51 & 50 & 52 & 52 \\
\hline CMAP $(N \geq 5)$ & 7 & 6 & 7 & 3.6 & 10 & 11 & 9 \\
\hline \multicolumn{8}{|l|}{ Peroneal } \\
\hline $\operatorname{MCV}(N \geq 42)$ & 39 & 42 & 29 & 40 & 51 & 48 & 51 \\
\hline CMAP $(N \geq 3)$ & 1 & 6 & 7 & 4.1 & 9 & 6 & 4.8 \\
\hline $\operatorname{SCV}(N \geq 42)$ & 48 & 50 & 47 & 52 & 50 & 51 & $50 /$ \\
\hline $\operatorname{SNAP}(N \geq 12)$ & 8 & 18 & 1 & 19 & 15 & 18 & 18 \\
\hline \multicolumn{8}{|l|}{ Peroneal } \\
\hline $\operatorname{SCV}(N \geq 42)$ & 31 & 42 & Absent & 38 & 42 & 42 & 62 \\
\hline $\operatorname{SNAP}(N \geq 10)$ & 1 & 12 & Absent & 21 & 21 & 18 & 17.5 \\
\hline Phrenic nerve latency: $R / L(N \leq 7.5 \pm 0.60)$ & $17.8 / 14.9$ & $\mathrm{Nd}$ & $10.2 / 15.2$ & $\mathrm{Nd}$ & $\mathrm{Nd}$ & $\mathrm{Nd}$ & $\mathrm{Nd}$ \\
\hline Valsalva ratio $(N \geq 1.40)$ & 1.15 & $\mathrm{Nd}$ & 1.20 & $\mathrm{Nd}$ & $\mathrm{Nd}$ & $\mathrm{Nd}$ & $\mathrm{Nd}$ \\
\hline SSR (on foot, $N \geq 2 \pm 0.3$ ) & Absent & 2.2 & Absent & 2 & 2.1 & 2 & 2.2 \\
\hline
\end{tabular}

$\mathrm{MCV}$, motor nerve conduction velocity $(\mathrm{m} / \mathrm{s})$; SCV, sensory nerve conduction velocity (m/s); CMAP, compound muscle action potential (mV); SNAP, sensory nerve action potential $(\mu \mathrm{V})$; SSR, sympathetic skin reflex recorded after median nerve stimulation (m/s); As, asymptomatic; R, right; L, left; Nd, not done.

\subsection{Bladder and pulmonary function tests}

Patients $\mathrm{II}_{1}$ and $\mathrm{II}_{3}$ complained of urinary urgency, dysuria and incontinence, requiring a protective device. They underwent a cystometrogram, which showed a bladder dysfunction characterized by a marked reduced flow, an elevated post-void residue and detrusor hyporeflexia. An urological examination and, in the case of patient $\mathrm{II}_{1}$, a gynecological examination ruled out other causes of urinary incontinence, such as urinary infection, urinary tract lesions, urinary lithiasis, pelvic organ prolapse or prostatic obstruction. Both patients were therefore trained to perform intermittent self-catheterization. They also complained of headaches, daytime tiredness and sleepiness. The chest $\mathrm{X}$-ray was normal. Electrocardiogram and cardiological

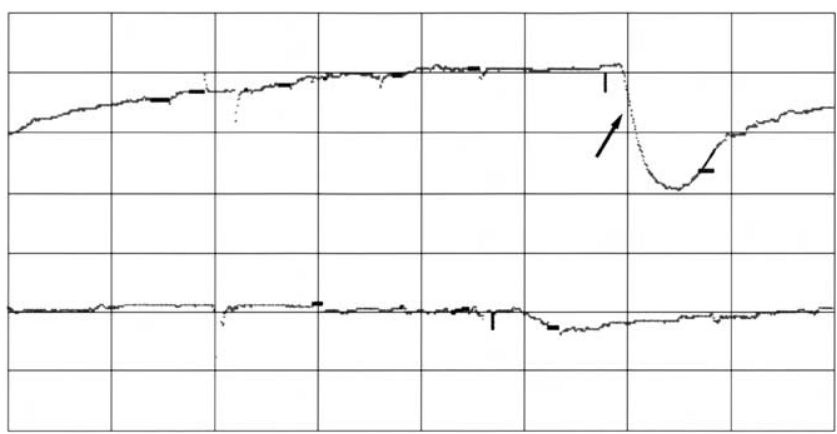

Fig. 2. Pupillometric tests. The figure shows pupillary contraction (arrow), characterized by an amplitude of $2.22 \mathrm{~mm}$ and a PLRL latency of $320 \mathrm{~ms}$, after light stimulation in normal individual $\mathrm{II}_{2}$ (upper line), in contrast to the lack of pupillary contraction in patient $\mathrm{II}_{3}$ (lower line). Reference values: PLRL latency (ms) in controls (mean \pm SD): $260.3 \pm 62.1$. Contraction amplitude (mean $\pm \mathrm{SD}): 2.34 \pm 3.2 \mathrm{~mm}$. examination ruled out cardiac impairment. As regard to the dyspnea, neither patient $\mathrm{II}_{1}$ nor patient $\mathrm{II}_{3}$ was addicted to tobacco. The spirometry results of these two patients showed a reduced forced vital capacity, forced expiratory volume, vital capacity and forced expiratory flow. The residual volume was elevated in both patients. Nocturnal sleep disruption and episodes of desaturation (mean $\mathrm{SaO}_{2}$ : $89 \%$ ) were also reported. Blood arterial gas analysis showed elevated $\mathrm{PaCO}_{2}$ and reduced $\mathrm{PaO}_{2}$, which was particularly marked during the night and in the early morning in patient $\mathrm{II}_{1}$.

\subsection{Biological and nerve biopsy results}

The nerve biopsy showed a marked loss of large myelinated fibers and numerous clusters of regenerating fibers. There were also a few large clusters, which had previously been misinterpreted as onion bulb formations. Electron microscopy confirmed the presence of these large clusters of regenerating fibers. Blood tests ruled out syphilis and the common causes of peripheral neuropathy.

\subsection{Genetic analysis}

Screening for the Thr124Met mutation in the $M P Z$ gene was performed by PCR-restriction in the individuals in the French arm of the family, as previously described for the members of the Belgian arm of the family (De Jonghe et al., 1999). This mutation creates an Nla III restriction site, allowing it to be detected by digestion of the PCR product of exon 3 . The mutation was present in patients $\mathrm{II}_{1}$ and $\mathrm{II}_{3}$ and absent in at-risk individuals $\mathrm{II}_{2}, \mathrm{II}_{4}, \mathrm{III}_{9}, \mathrm{III}_{10}$ and $\mathrm{III}_{11}$. 


\section{Discussion}

In this study, we report the clinical features of a CMT family carrying a point mutation in codon $124(\mathrm{Thr} \rightarrow \mathrm{Met})$ in the $M P Z$ gene. The clinical presentation is consistent with a sensorimotor polyneuropathy associated with autonomic disturbances, characterized by bladder dysfunction and hypotension. Several points have already been emphasized in CMT patients with Thr124Met mutation: late onset with symptoms starting in the fourth or fifth decade, symptoms characterized by a marked weakness predominantly in the lower limbs associated with severe pain unresponsive to conventional therapy and abolished pupil reflex (De Jonghe et al., 1999). Our family presents a particular phenotype associating two additional symptoms which are unusual in CMT patients: bladder dysfunction and respiratory failure requiring noninvasive mechanical ventilation.

In the past, the pupillary abnormalities associated with pain and neuropathy led to the diagnosis of tabes dorsalis in the older generations. This symptom may also suggest amyloidosis or mellitus diabetes (Lanting et al., 1991). However, once the latter hypotheses have been excluded, patients should be investigated for $M P Z$ gene mutation. Abnormal or abolished pupillary reflex may be the first sign of CMT disease associated with $M P Z$ mutation, since asymptomatic carriers may present pupillary abnormalities before they reach the age of onset (De Jonghe et al., 1999). Deafness was an additional phenotypic feature in previously reported families (Chapon et al., 1999; Misu et al., 2000; Mastaglia et al., 1999; De Jonghe et al., 1999). Although seldom described in CMT patients, involvement of the cochlear nerve has been reported in different forms of CMT, whether demyelinating or axonal (Pareyson et al., 1995).

Of particular interest is the bladder dysfunction in patient $\mathrm{II}_{1}$, which occurred before the clinical symptoms of neuropathy. Bladder dysfunction is a common feature of several acquired peripheral neuropathies, such as diabetes, Guillain-Barré disease and primary amyloidosis. In the case of inherited neuropathies, they are more commonly observed in familial amyloidosis, porphyria and hereditary autonomic and sensory neuropathy (Dyck et al., 1993). Bladder dysfunction has never previously been reported in CMT1B. Even the affected members of the previously reported Belgian branch of our family never reported these urinary disturbances (De Jonghe et al., 1999). Nevertheless, bladder dysfunction may have been underestimated in HMSN involving the $M P Z$ gene, since patients are rarely questioned about micturition disturbances in these diseases. The other unusual manifestation in this CMT family is respiratory failure. Respiratory insufficiency is a common manifestation of neuromuscular diseases such as GuillainBarré disease or myasthenia. However, in chronic diseases such as HMSN, respiratory failure is reported in the axonal form of CMT, classified as CMT2C and characterized by diaphragmatic and vocal cord paralysis (Nagamatsu et al., 2000). It has also been reported in a patient with a severe form of CMT2 (Gilchrist et al., 1989). As observed in our two affected patients, respiratory failure is mainly due to diaphragmatic weakness consecutive to phrenic nerve palsy.

Mutations in the $M P Z$ gene account for various demyelinating forms of CMT disease, such as CMT1B, Dejerine-Sottas disease or congenital hypomyelination, and are in accordance with the proposed function of this protein in myelin compaction. However, our study and previous ones suggest that the $M P Z$ gene may also be involved in the autonomic system, the postganglionic sympathetic and parasympathetic axons of which are known to be unmyelinated (Hagedorn et al., 1999). P0 protein is the major structural component of peripheral nervous system myelin. The extracellular domain of P0 is involved in the compaction of the myelin sheath (Filbin et al., 1990). However, the expression of P0 is not confined to Schwann cells that will myelinate axons, as it has also been detected during development in nonmyelinating glial cells of the peripheral nervous system, such as satellite cells in sympathetic and trigeminal ganglia (Filbin et al., 1990; Sommer and Suter, 1998; Hagedorn et al., 1999). Since P0 is expressed long before the onset of myelination, other functions have been speculated upon. However, the pupillary dysfunction observed in our affected patients could be explained by a myelin defect of postganglionic parasympathetic fibers, originating from the EdingerWestphal nucleus, since these fibers are thinly myelinated (Hanemann et al., 2001).

Furthermore, in P0 null mice the absence of functional P0 protein results in demyelination and also affects axons, which show reduced caliber and degeneration with increasing age (Giese et al., 1992). A recent study suggests that a loss of an important peripheral myelin component can also initiate degenerative mechanisms in distal portions of axons, leading to the loss of specialized receptor end organs, such as nociceptors, and thus to impaired muscle innervation (Frei et al., 1999). This may account for severe pain requiring narcotic drugs and may suggest a dysfunction of $\mathrm{A} \delta$ fibers, the afferent neurons of which are referred to as nociceptors. However, pain is not a specific sign of this form of CMT neuropathy since this symptom has been reported in $71 \%$ of CMT patients, $39 \%$ of whom complained of disability due to this pain (Carter et al., 1998). On the basis of the clinical data and the electrophysiological results of the nerve conduction studies, our family could have been classified as having a sensorimotor axonal form of CMT with autonomic dysfunction. In this respect, the serine palmitoyltransferase long chain base subunit-1 gene was recently associated with an autosomal dominant form of hereditary sensory and autonomic neuropathy (Bejaoui et al., 2001; Dawkins et al., 2001), which does not however, share the electrophysiological features of the affected individuals of our family, who had significantly reduced motor conduction velocities. Indeed, several CMT families carrying an $M P Z$ gene mutation and showing an axonal phenotype with late onset have been described (Marrosu et al., 1998; 
Chapon et al., 1999; Mastaglia et al., 1999; De Jonghe et al., 1999; Misu et al., 2000). On the basis of this new phenotype, this form of CMT with MPZ gene mutation has been classified in the group of axonal form or CMT2 (Gemignani and Marbini, 2001). However, our results emphasize the phenotypic heterogeneity of CMT associated with Thr124Met mutation, since such autonomic disturbances and respiratory dysfunction have not previously been reported. This particular phenotype suggests an axonal dysfunction caused by the Thr124Met mutation in the MPZ gene and supports the hypothesis that P0 is not only involved in myelin compaction but also plays a role in axonal integrity. The function of P0 protein is incompletely understood, and further studies are needed to clarify the physiopathological mechanism involving $\mathrm{P} 0$ in the somatic and autonomic nervous system.

\section{References}

Bejaoui K, Wu C, Scheffler MD, Haan G, Ashby P, Wu L, et al. SPTLC1 is mutated in hereditary sensory neuropathy type I. Nat Genet 2001;27: 261-2.

Ben Othmane K, Middleton LT, Loprest LJ, Wilkinson KM, Lennon F, Rozear MP, et al. Localization of a gene (CMT2A) for autosomal dominant Charcot-Marie-Tooth disease type 2 to chromosome $1 \mathrm{p}$ and evidence of genetic heterogeneity. Genomics 1993;17:370-5.

Carter GT, Jensen MP, Galer BS, Kraft GH, Crabtree LD, Beardsley RM, et al. Neuropathic pain in Charcot-Marie-Tooth disease. Arch Phys Med Rehabil 1998;79:1560-4.

Chapon F, Latour P, Diraison P, Schaeffer S, Vandenberghe A. Axonal phenotype of Charcot-Marie-Tooth disease associated with a mutation in the myelin protein zero gene. J Neurol Neurosurg Psychiatry 1999;66:779-82.

Cruz-Martinez A, Armijo A, Fermoso A, Moradela S, Mate I, Marin M. Phrenic nerve conduction study in demyelinating neuropathies and heart surgery. Clin Neurophysiol 2000;111:831-5.

Dawkins JL, Hulme DJ, Brahmbhatt SB, Auer-Grumbach M, Nicholson GA. Mutations in SPTLC1, encoding serine palmitoyltransferase long chain base subunit-1, cause hereditary sensory neuropathy type 1 . Nat Genet 2001;27:309-12.

De Seze J, Arndt C, Stojkovic T, Ayachi M, Gauvrit JY, Bughin M, et al. Pupillary disturbances in multiple sclerosis: correlation with MRI findings. J Neurol Sci 2001;188:37-41.

De Jonghe P, Timmerman V, Ceuterick C, Nelis E, De Vriendt E, Löfgren A, et al. The Thr124Met mutation in the peripheral myelin protein zero (MPZ) gene is associated with a clinically distinct Charcot-MarieTooth disease. Brain 1999;122:281-90.

Dyck PJ, Chance P, Lebo R, Carney JA. Hereditary motor and sensory neuropathies. In: Dyck PJ, Thomas PK, Griffin JW, Low PA, Poduslo JF, editors. Peripheral neuropathy, 3rd ed. Philadelphia, PA: Saunders; 1993. p. 1094-136.

Filbin MT, Walsh FS, Trapp BD, Pizzey JA, Tennekoon GI. Role of myelin P0 protein as a homophilic adhesion molecule. Nature 1990;344:871-2.

Frei R, Mötzing S, Kinkelin I, Schachner M, Kotzenburg M, Martini R. Loss of distal axons and sensory merkel cells and features indicative of muscle denervation in hindlimbs of P0-deficient mice. J Neurosci 1999; 19:5058-6067.

Gemignani F, Marbini A. Charcot-Marie-Tooth disease (CMT): distinctive phenotypic and genotypic features in CMT type 2. J Neurol Sci 2001;184:1-19.

Giese KP, Martini R, Lemke G, Soriano P, Schachner M. Mouse P0 gene disruption leads to hypomyelination, abnormal expression of recognition molecules, and degeneration of myelin and axons. Cell 1992;71:565-76.

Gilchrist D, Chan CK, Deck JH. Phrenic involvement in Charcot-MarieTooth disease. A pathological documentation. Chest 1989;96:1197-9.

Hagedorn L, Suter U, Sommer L. P0 and PMP22 mark a multipotent neural crest-derived cell type that displays community effects in response to TGF-beta family factors. Development 1999;126:3781-94.

Hanemann CO, Gabreëls-Festen AAWM, De Jonghe P. Axon damage in CMT due to mutation in myelin protein P0. Neuromuscul Disord 2001; 11:753-6.

Hayasaka K, Himoro M, Sato W, Takada G, Uyemura K, Shimizu N, et al. Charcot-Marie-Tooth neuropathy type $1 \mathrm{~B}$ is associated with mutations of the myelin P0 gene. Nat Genet 1993;5:31-41.

Ionasescu V, Searby C, Sheffield VC, Roklina T, Nishimura D, Ionasescu R. Autosomal dominant Charcot-Marie-Tooth axonal neuropathy mapped on chromosome 7p (CMT2D). Hum Mol Genet 1996;5:1373-5.

Kwon JM, Elliott JL, Yee WC, Ivanovich J, Scavarda NJ, Moolsintong PJ, et al. Assignment of a second Charcot-Marie-Tooth type II locus to chromosome 3q. Am J Hum Genet 1995;57:853-8.

Lanting P, Strijers RL, Bos JE, Faes TJ, Heimans JJ. The cause of increased pupillary light reflex latencies in diabetic patients and the relationship between pupillary light reflex and visual evoked potential latencies. Electreoenceph clin Neurophysiol 1991;78:111-5.

Latour P, Blanquet F, Nelis E, Bonnebouche C, Chapon F, Diraison P, et al. Mutations in the myelin protein zero gene associated with CharcotMarie-Tooth disease type 1B. Hum Mutat 1995;6:50-4.

Low PA. Autonomic nervous system function. J Clin Neurophysiol 1993; 10:14-27.

Marrosu MG, Vaccargiu S, Marrosu G, Vanelli A, Cianchetti C, Muntoni F. Charcot-Marie-Tooth disease type 2 associated with mutation of the myelin protein zero gene. Neurology 1998;50:1397-401.

Mastaglia FL, Nowak KJ, Stell R, Philips BA, Edmondston JE, Dorosz SM, et al. Novel mutation in the myelin protein zero gene in a family with intermediate hereditary motor and sensory neuropathy. J Neurol Neurosurg Psychiatry 1999;67:174-9.

Misu K, Yoshihara T, Shikama Y, Awaki E, Yamamoto M, Hattori M, et al. An axonal form of Charcot-Marie-Tooth disease showing distinctive features in association with mutations in the peripheral myelin protein zero gene (Thr124Met or Asp75Val). J Neurol Neurosurg Psychiatry 2000;69:806-11.

Nagamatsu M, Jenkins RB, Shaid DJ, Klein DM, Dyck PJ. Hereditary and sensory neuropathy type $2 \mathrm{C}$ is genetically distinct from type $2 \mathrm{~B}$ and $2 \mathrm{D}$. Arch Neurol 2000;57:669-72.

Pareyson D, Scaioli V, Berta E, Sghirlanzoni A. Acoustic nerve in peripheral neuropathy: a BAEP study. Brainstem auditory evoked potentials. Electromyogr Clin Neurophysiol 1995;35:359-64.

Senderek J, Hermanns B, Lehmann U, Bergmann C, Marx G, Kabus C, et al. Charcot-Marie-Tooth neuropathy type 2 and P0 point mutations: two novel amino-acid substitutions (Asp61Gly: Tyr119Cys) and a possible "hotspot" on Thr124Met. Brain Pathol 2000;10:235-48.

Sommer L, Suter U. The glycoprotein P0 in peripheral gliogenesis. Cell Tissue Res 1998;292:11-16.

Timmerman V, Nelis E, Van Hul W, Nieuwenhuijsen BW, Chen KL, Wang $\mathrm{S}$, et al. The peripheral myelin protein gene $P M P 22$ is contained within the Charcot-Marie-Tooth disease type 1A duplication. Nat Genet 1992;1:171-5.

Valentijn LJ, Baas F, Wolterman RA, Hoogendijk JE, van den Bosch NH, Zorn I, et al. Identical point mutations of PMP22 in Trembler-J mouse and Charcot-Marie-Tooth disease type 1B. Nat Genet 1992;2:288-91.

Warner LE, Hilz MJ, Appel SH, Killian JM, Kolodry EH, Karpati G, et al. Clinical phenotypes of different MPZ (P0) mutations may include Charcot-Marie-Tooth type 1B, Dejerine-Sottas, and congenital hypomyelination. Neuron 1996;17:451-60.

Young P, Grote K, Kuhlenbaumer G, Debus O, Kurlemann H, Halfter H, et al. Mutations analysis in Charcot-Marie-Tooth disease type I: point mutations in the MPZ and the GBJ1 gene cause comparable phenotypic heterogeneity. J Neurol 2001;248:410-5. 